\title{
EARTH FILL INCREASES EFFICACY AND LONGEVITY OF A-CYHALOTHRIN RESIDUAL INSECTCIDE TREATMENT OF HESCO® BLAST WALL GEOTEXTILE
}

\author{
SETH C. BRITCH ${ }^{1,2^{*}}$, JAMES E. CILEK ${ }^{1,3^{\dagger},}$ ERICA J. LINDROTH ${ }^{3}$, \\ ROBERT L. ALDRIDGE², FRANCES V. GOLDEN², JOSHUA R. WESTON ${ }^{3}$, \\ JASON D. FAJARDO ${ }^{3}$, ALEC G. RICHARDSON ${ }^{3}$, JESSIKA S. BLERSCH ${ }^{4}$, \\ AND KENNETH J. LINTHICUM² \\ 'Co-senior authors of this work
}
${ }^{2}$ US Department of Agriculture, Agricultural Research Service Center for Medical, Agricultural, and Veterinary Entomology, 1600 SW 23rd Drive, Gainesville, FL 32608

${ }^{3}$ Navy Entomology Center of Excellence, Box 43, 937 Child Street, Jacksonville, FL 32212
${ }^{4}$ Camp Blanding Joint Training Center, Florida Army National Guard, 5629 State Road 16W, Starke, FL 32091

Subiect Editor: Rui-De Xue

*Corresponding author: Seth C. Britch

USDA-ARS-CMAVE, 1600 SW 23 ${ }^{\text {rd }}$ Dr., Gainesville, FL 32608

seth.britch@usda.gov

\begin{abstract}
The prevention of vector-borne disease to protect the health and readiness of United States forces in the field continues to be a high priority for the US Department of Defense. Previous studies have demonstrated that the risk of human contact with disease-vector mosquitoes and other biting flies can be reduced by applying an insecticide to perimeters of military materials such as camouflage netting or HESCO blast protection wall geotextile already in place around troops in the field. In this study we investigated whether residual pesticide efficacy will persist in the presence of earth fill that is required for operational use of HESCOs, using a warm temperate field site in north Florida. Results from laboratory bioassays measuring mosquito mortality and field collections of natural mosquito populations indicated superior efficacy and greater longevity of pesticide treated geotextile exposed to soil fill. These findings not only support immediate implementation of this technique in US military field scenarios, but also provide evidence that HESCO technology currently used in natural disaster flood control could be leveraged to protect civilian personnel from emerging floodwater mosquitoes.
\end{abstract}

Key Words: Military operational entomology, passive control, deployment, barrier treatment, flood control, natural disaster

${ }^{+}$The views expressed in this article are those of the authors and do not necessarily reflect the official policy or position of the Department of the Navy, Department of Defense, nor the U.S. Government. All authors are employees of the U.S. Government. This work was prepared as part of their official duties. Title 17, U.S.C., \$105 provides that copyright protection under this title is not available for any work of the U.S. Government. Title 17, U.S.C., \$101 defines a U.S. Government work as a work prepared by a military Service member or employee of the U.S. Government as part of that person's official duties. 


\section{INTRODUCTION}

Arthropod-borne diseases such as malaria or leishmaniasis transmitted to humans from the bites of infected mosquitoes or sand flies, respectively, continue to pose significant threat to United States (US) military personnel worldwide (Kitchen et al. 2009; Stoops et al. 2013; Garcia et al. 2017). Lacking effective or approved vaccines for these and other high-risk arthropod-borne pathogens such as Zika, chikungunya, or dengue viruses the best strategy for reducing disease risk is to reduce contact between humans and arthropod vectors (Scott and Morrison 2004; Eisen et al. 2009; World Health Organization 2014). Strategies designed to reduce contact with disease vectors may also improve morale and reduce impact of nuisance populations of mosquitoes and filth flies on US military missions.
One method to reduce risk of human contact with infected mosquitoes or sand flies is to create a protective barrier around personnel in the field by applying residual insecticides to existing vegetation or perimeter structures (Frances 2007; Xue 2008; Britch et al. 2010, 2011, 2018). A common perimeter structure used worldwide by the US military is the HESCO MIL® blast wall system (Szabó et al. 2011; HESCO Bastion, Inc. 2019), that consists of a welded steel cage lined with a durable nonwoven polypropylene geotextile (Müller and Saathoff 2015) packed with earth fill removed from the surrounding terrain (Figure 1). Such perimeters can be exploited as targets for control because mosquitoes or sand flies have been observed to rest there (Britch et al. 2018) and HESCO walls typically surround outdoor locations where personnel are present in US military expeditionary installa-

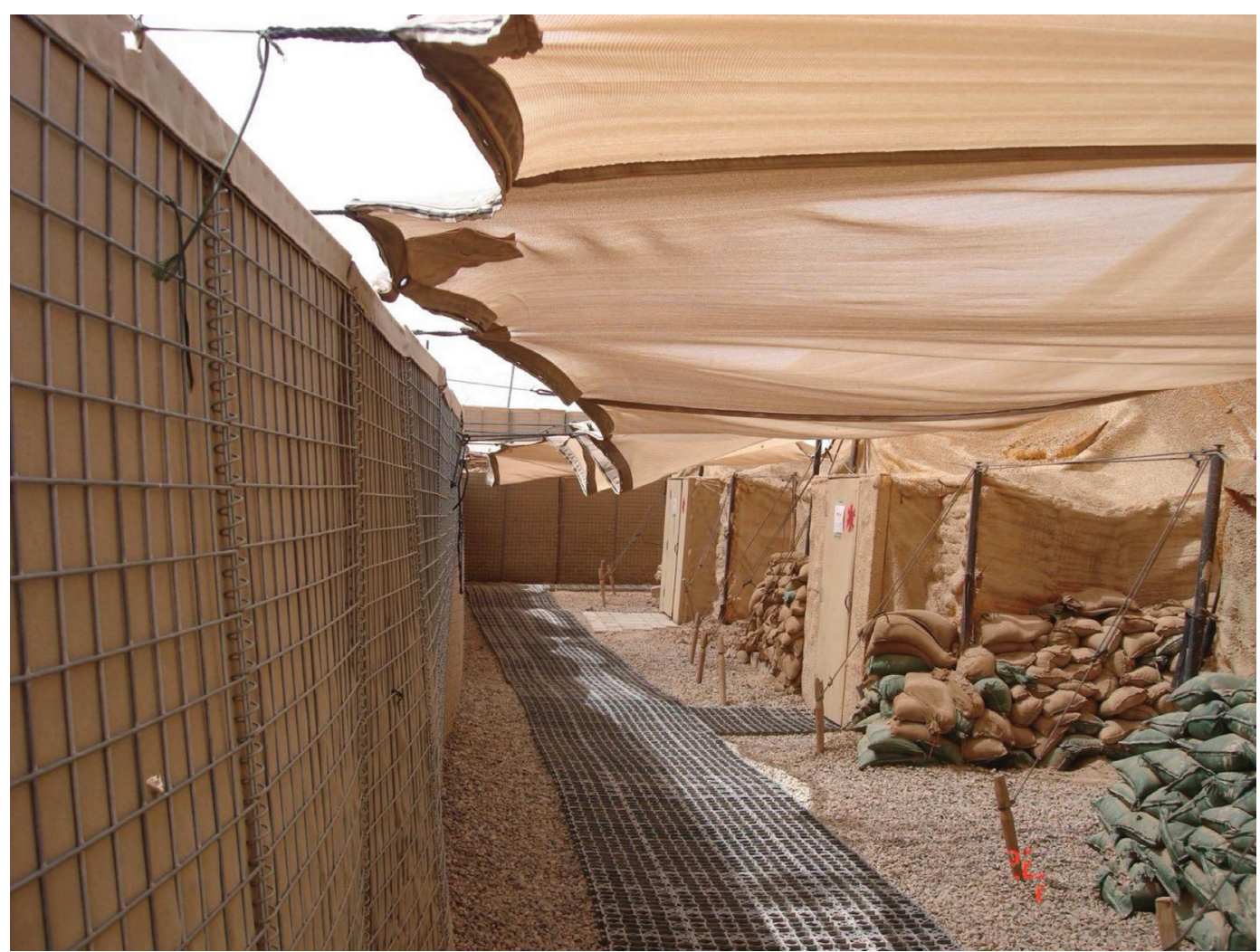

Figure 1. A HESCO perimeter at a US military outpost in southern Iraq, 2009. The HESCO wall is seen on the left and in the far background. A narrow walkway separates this structure from tents and other living areas to the right. 
tions. Furthermore, preliminary testing of resting surface affinity of laboratory colonies of disease vector Phlebotomus papatasi sand flies revealed that they preferentially rest on HESCO geotextile, compared to other common US military field materials such as camouflage netting, plywood, or concrete (M. L. Aubuchon, unpublished data).

A recent study (Britch et al. 2018) demonstrated that HESCO geotextile treated with $\lambda$-cyhalothrin may be effective against mosquitoes and sand flies for up to 45 days during exposure to warm temperate conditions in the field. Additional data from a related field study showed that HESCO geotextile treated with $\lambda$-cyhalothrin substantially reduced host-seeking natural populations of Phlebotomus spp. sand flies, compared with untreated HESCO geotextile in a dry hot environment in western Kenya (SCB, KJL, unpublished data). Although the residual efficacy of this treatment on HESCO geotextile material has been demonstrated against mosquitoes and sand flies in the laboratory and field, those prior studies did not investigate efficacy of $\lambda$-cyhalothrin applied to HESCO packed with earth fill as they would be in a US military field scenario (Britch et al. 2018). It is possible that the presence of soil could alter moisture content of the geotextile or facilitate transfer of microbes or dissolved soil chemistry constituents into the geotextile fabric, potentially affecting (positively or negatively) the pesticide itself or the capacity of the material to retain an effective residual treatment against mosquitoes.

Another prominent scenario where perimeters of HESCO MIL cells are used is in natural disaster response to create floodresistant berms. Modular units of these cells were used in 2005 to successfully reinforce levees around New Orleans in the few days between Hurricane Katrina and Hurricane Rita (Gibson 2006; US Army Corps of Engineers 2006). Following an extreme weather event such as a hurricane, these berms are often placed adjacent to flood prone areas of potential habitat for immature floodwater mosquitoes. If these structures were treated with insecticides they could provide a first line of residual protection against newly emerged adult mosquitoes as they leave their immature habitat to seek their first blood meals. A residual insecticide treatment on earth filled HESCO flood control berms would need to remain effective despite persistent contact with moist soil.

In this study we investigated the relative performance of soil-filled HESCO MIL cells compared with unfilled units treated with $\lambda$-cyhalothrin for reducing natural populations of disease vector mosquitoes in a warm temperate field site in north Florida. We hypothesized that the presence of earth fill in HESCO MIL cells could affect (positively or negatively) the longevity and/or residual efficacy of the pesticide treatment, providing key data to guide future military operational or natural disaster response use.

\section{MATERIALS AND METHODS}

We designed small simulated HESCO MIL perimeters to study the effects of soil fill on the capability of HESCO geotextile treated with a residual pesticide to reduce penetration of a finite protected space by natural populations of disease vector mosquitoes. These perimeters were similar to but larger than the HESCO enclosures used by Britch et al. (2018). Each perimeter consisted of 22 woodland green geotextile 0.9

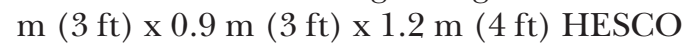
MIL cells (HESCO Bastion, Ltd.; Charleston, SC) arranged in two tiers of 11 cells to enclose a protected $1.8 \mathrm{~m}(6 \mathrm{ft}) \times 1.8 \mathrm{~m}(6$ ft) $\times 2.5 \mathrm{~m}(8 \mathrm{ft})$ interior space, with a gap near one corner for access (Figure 2). We constructed doors to cover the gap in each perimeter by breaking down extra HESCO MIL cells into sets of two $0.9 \mathrm{~m} \times 1.2 \mathrm{~m}$ panels joined vertically along their short sides (Figure 2). All HESCO perimeters were secured and stabilized using steel hog rings linking the upper and lower tiers and steel cables threaded through the HESCO steel mesh connected to large steel pins screwed into the ground.

We identified 16 sites for the HESCO perimeters evenly distributed across two study plots -8 sites in a southern plot centered on $29.888190^{\circ} \mathrm{N}, 82.045735^{\circ} \mathrm{W}$ and 8 in a 


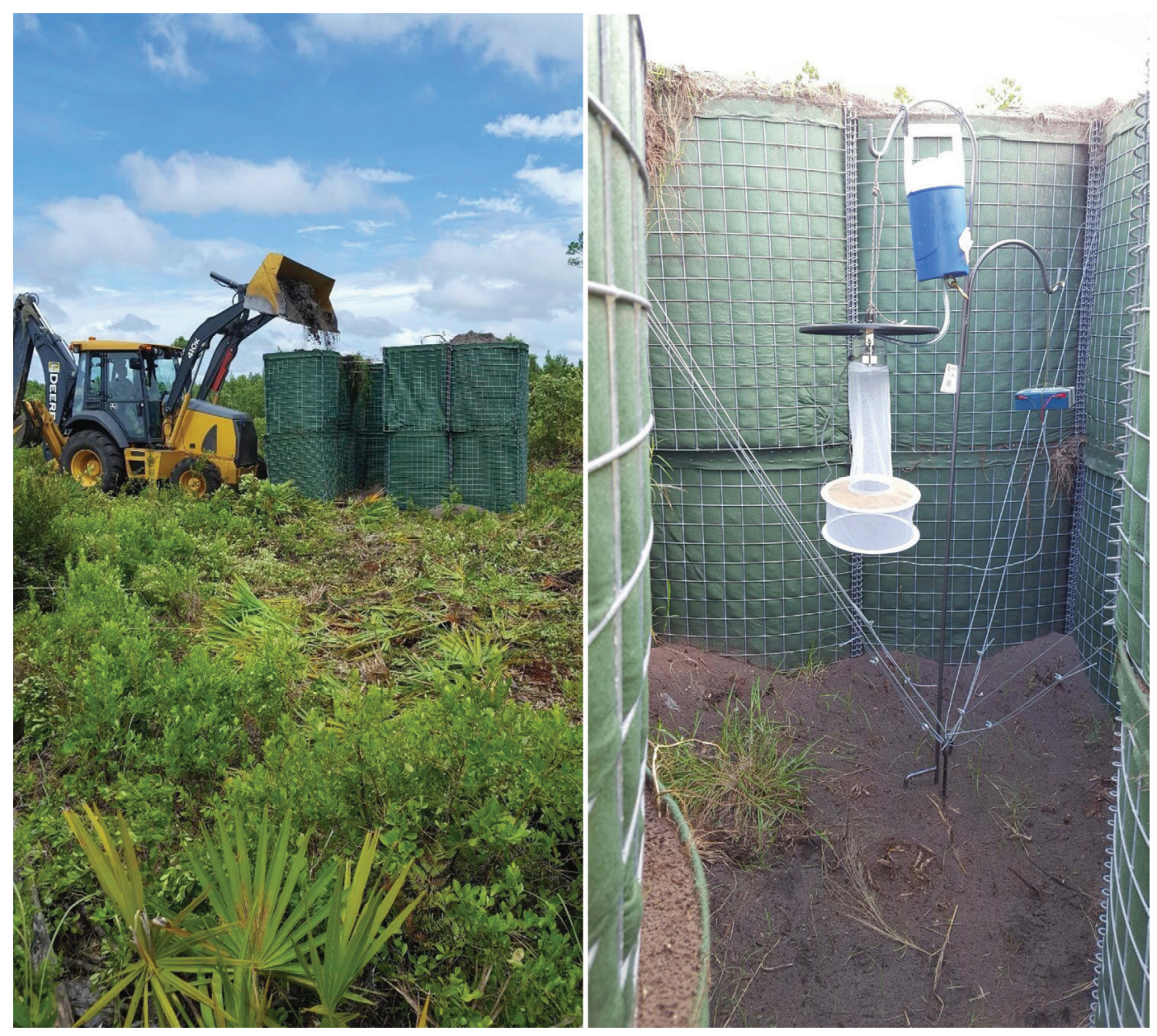

Figure 2. One of 16 two-tiered HESCO perimeters under construction at Camp Blanding Joint Training Center, Starke, FL (left hand image). Access door made of two stacked side panels from a broken-down HESCO MIL cell is visible at left front of this perimeter. Right hand image shows placement of a CDC light trap baited with dry ice to sample mosquito populations inside a soil filled HESCO perimeter.

northern plot centered on $29.890552^{\circ} \mathrm{N}$, $82.045720^{\circ} \mathrm{W}$ - in freshwater swamp land east of a remote dirt road parallel to the western boundary of Camp Blanding Joint Training Center (CBJTC), Starke, Florida (Figure S1; Supplementary Materials available at https://www.ars.usda.gov/cmave/ $\mathrm{mfru} / \mathrm{HESCO})$. The centroids of the two plots were separated by approximately 500 m. A controlled burn had been conducted in the area several years earlier causing considerable emergent shrubs, forbs, and other natural vegetation from $0.5-3.0 \mathrm{~m}$ in height throughout and between the plots. Due to the presence of standing water throughout the study area, we situated the 16 perimeter sites on available fragments of slightly elevated, dry ground that separated all perimeter sites in each plot by approximately 9-12 $\mathrm{m}$.

Prior to installation of the perimeters we conducted mosquito surveys that confirmed both study plots were situated in areas highly productive for natural populations of medically important mosquito species. From 1827 July 2016 (six 24 h collection periods) we suspended US Centers for Disease Control and Prevention (CDC) style suction traps (J. W. Hock Co., Gainesville, FL) baited with 1.3 $\mathrm{kg}$ dry ice and light $1.2 \mathrm{~m}$ from the ground at the 4 cardinal directions around the approximate boundary of each plot (L1-L8; Figure $3)$. We identified all collections to species 

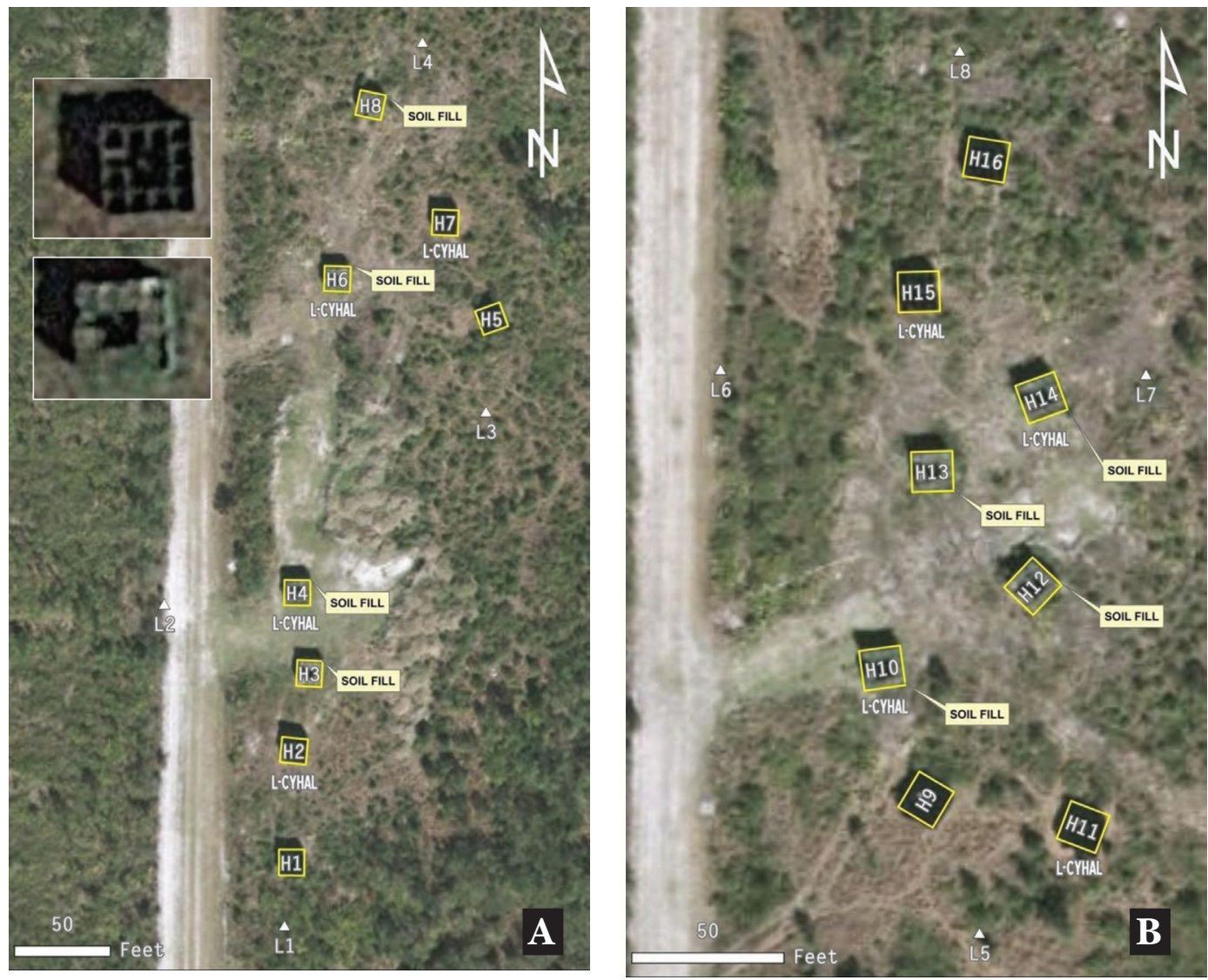

Figure 3. Detailed views of (A) the southern and (B) the northern experimental plots. Outside CDC traps are indicated with small white triangles labeled L1-L4 (southern plot) and L5-L8 (northern plot). HESCO perimeters filled with soil and treated perimeters are indicated with labels. Insets in (A) show close up aerial views of an unfilled (inset-upper) and soil-filled (inset lower) HESCO perimeter.

from these 8 traps using the taxonomic keys of Darsie and Morris (2003).

We randomly assigned 4 of the 8 perimeter sites in each plot to situate soil-filled perimeters, with the other 4 sites in each plot for unfilled perimeters. In each plot, we randomly designated 2 soil-filled and 2 unfilled perimeters for treatment with residual pesticide. Therefore, across the southern and northern plots combined we created 4 experimental classes of HESCO perimeters: soil-filled/untreated ( $\mathrm{N}=4)$, soil-filled/residual insecticide treated $(\mathrm{N}=4)$, unfilled/untreated $(\mathrm{N}=4)$, and unfilled/residual treated $(\mathrm{N}=4)$ (Figure 3).

On 27 July 2016 we constructed 4 unfilled and untreated HESCO MIL perimeters, 2 in the southern plot H-1 and H-5 (Figure 3A); and 2 in the northern plot H-9 and H-16 (Fig- ure 3B). On 6 August 2016 we constructed 4 soil-filled and untreated HESCO perimeters: 2 in the southern plot $\mathrm{H}-3$ and $\mathrm{H}-8$ and 2 in the northern plot $\mathrm{H}-12$ and H-13. The soil had been trucked in and stored in heaps at the two plots for this experiment from routine CBJTC Environmental Department forestry operations over the previous several months and was similar to the ambient undifferentiated sand and clay soil (Dearstyne et al. 1991) observed at the site. We used a frontend loader to transfer soil into HESCO cells, first constructing and filling the lower 11-cell layer, then carefully constructing, filling, and anchoring the upper 11-cell layer in each soilfilled HESCO perimeter. We constructed the 4 unfilled treated HESCO MIL perimeters (H-2 and H-7 in the southern plot; $\mathrm{H}-11$ and H-15 in the northern plot) on 11-12 August 
2016 and the 4 soil filled and treated HESCO MIL perimeters (H-4 and $\mathrm{H}-6$ in the southern plot; $\mathrm{H}-10$ and $\mathrm{H}-14$ in the northern plot) on 18-19 August 2016, after the residual treatment was applied to individual HESCO MIL cells on 9 August 2016 (see below).

We conducted two separate trials with the HESCO MIL perimeters, each lasting several months. In Trial 1, we treated HESCO MIL cells individually on 9 August 2016 with $\lambda$-cyhalothrin (Demand CS; Syngenta, Greensboro, NC) at the maximum label rate of $0.8 \mathrm{fl} \mathrm{oz} / 1000 \mathrm{ft}^{2}\left(23.7 \mathrm{ml} / 93 \mathrm{~m}^{2}\right)$ in water using a backpack mist blower (SR450; STIHL Inc., Virginia Beach, VA) before they were assembled into the 8 treated ( 4 soil-filled and 4 unfilled) perimeters as described above. The sides of each HESCO MIL cell that would be facing other cells in these perimeters were not treated. However, both the outward and inward facing sides of each cell were all treated and clearly marked before assembly. For Trial 2, we treated the inward and outward facing sides of the 8 finished HESCO MIL treated perimeters in place on 9 November 2016 with the same sprayer, formulation, and application rate.

We used 2 methods to measure the relative effect of soil on the longevity and efficacy of the treated HESCO MIL geotextile. First, we placed a CDC trap baited with light and $\mathrm{CO}_{2}$ (dry ice) for $24 \mathrm{hr}$ in the center of the protected space in all 16 HESCO perimeters to periodically survey the overnight penetration of the perimeters by natural populations of medically important mosquitoes. Second, at the time of mosquito collection we cut $\sim 15$ $\mathrm{cm} \times 15 \mathrm{~cm}$ samples of geotextile from the inside and outside facing surfaces of each perimeter and exposed them to laboratory colony Culex quinquefasciatus females in glass tube bioassays at the USDA Agricultural Research Service Center for Medical, Agricultural, and Veterinary Entomology (CMAVE) following the methods and colony description of Aldridge et al. (2012, 2013) and Britch et al. (2009, 2010, 2011). We stored each cutting separately in labeled re-sealable bags to minimize opportunity for cross-contamination of samples. We collected the first geotextile cuttings on 18 August 2016 from all perim- eters before soil fill was introduced. We set a minimum benchmark of $80 \%$ mortality in bioassays to determine residual efficacy of the pesticide treatment of HESCO perimeters (Britch et al. 2018).

We also deployed the 8 outside CDC traps (L1-L8; Figure 3) situated at the 4 cardinal directions around each of the two study plots in synchrony with the periodic CDC collections within the perimeters to verify presence of host seeking mosquitoes in the study area. We recorded local meteorology throughout the study from a permanent weather station $\sim 2.4$ $\mathrm{km}$ south of the southern plot at a separate research site in comparable habitat, supplemented during periods of malfunction by $\mathrm{Na}-$ tional Climate Data Center Climate Data Online (https://www.ncdc.noaa.gov/cdo-web/) from other weather stations within $20 \mathrm{~km}$ of the research site.

\section{Statistical Analysis}

Our hypotheses were that (a) insecticidetreated HESCO perimeters regardless of the presence of soil would have lower CDC light trap collection numbers and higher bioassay mortality than untreated perimeters, thus demonstrating protection of the interior space by the presence of the residual pesticide, and (b) treated HESCO perimeters with soil would show significantly different (larger or smaller) CDC light trap collections or bioassay mortality for a significantly different (longer or shorter) duration than treated perimeters without soil.

To compensate for inevitable organic differences between no fill and soil filled HES$\mathrm{CO}$ perimeters yet still be able to investigate comparative efficacy of these two classes, we calculated the percent reduction in collections in treated HESCO perimeters, compared with untreated HESCO perimeters for the "no soil" and the "soil filled" classes separately using the formula:

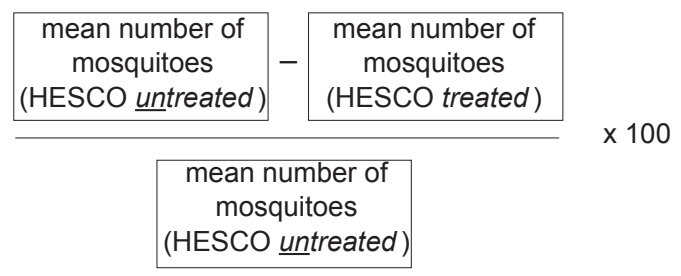


Using this formula, we could then directly compare the normalized reductions for no soil and soil to determine the effect of soil on efficacy and longevity of the residual insecticide treatment against natural mosquito populations. Initially, mean percent reduction data from Trials 1 and 2 were subjected to goodness-of-fit tests using the KolmogorovSmirnov and Bartlett tests. Results of these tests showed that datasets conformed to nonnormal and heteroscedastic behavior (even after data transformation). Hence, the nonparametric Kruskal-Wallis test was applied. Following the hypothesis test, an optimal post hoc multiple-comparison test was conducted for each of the factors and interactions to identify the specific pairwise combinations of levels of each factor and interaction contributing to the overall variability. Post hoc tests included Tukey multiple-comparison (Tukey, 1949, 1953), Newman-Keuls multiple-range (Newman, 1939), Duncan multiple-range (Duncan, 1951, 1955), and Scheffe multiplecontrast tests (Scheffe, 1953, 1959). Statistical analyses were performed using Intel Visual Fortran Compiler XE 2013 (Intel Corporation, Santa Clara, CA). Differences from these analyses were considered significant at $P \leq 0.05$. Non-transformed means are presented in tables and figures.

\section{RESULTS}

Light trap collections of natural mosquito populations

Across all traps inside and outside HESCO perimeters we collected 17 species of mosquitoes in Trial 1 (total 19,400 specimens; including the 6 pre-trial survey collections) and 19 species in Trial 2 (59,863 specimens) (Table S1). Overall mosquito abundance across the 8 CDC light traps placed outside of HESCO perimeters was significantly greater, compared with traps inside the HESCOs regardless of presence of soil (data not shown). Meteorological conditions were generally mild throughout both trials (Figure S2) with temperatures rarely exceeding the low $80 \mathrm{~s}^{\circ} \mathrm{F}\left(27-29^{\circ} \mathrm{C}\right)$ and very little precipitation. Humidity was variablehigh, frequently exceeding $80 \% \mathrm{RH}$ in both trials.
Field percent reduction efficacy results are shown in Figs. 4 and 5 for Trials 1 and 2, respectively. The majority of Trial 1 fell during a period of consistently high mosquito biting pressure (i.e., mean outside CDC trap collections >100; Figure 4). Therefore, Trial 1 efficacy data based on relative reductions in field collections are potentially informative from the time of treatment forward for several weeks, although bioassay data on cuttings suggest that the treatment was weak from the outset (see HESCO fabric bioassays results below and Figure 6 ). Bioassay data from Trial 2 suggest a much stronger residual treatment from the outset (Figure 7). Unfortunately, the majority of Trial 2 from the time of treatment (9 November 2016) forward occurred during winter months making it potentially difficult to resolve percent reduction levels against low natural population numbers (Figure 5) when the treatment was recent and at its strongest as shown by bioassays.

Using the summary data in Table S1 we initially restricted field efficacy analyses to species where at least $\sim 1,000$ specimens were collected in each trial, which generally indicated high biting pressure for that species early in the treatment period when residual efficacy in bioassays was highest (Figs. 6 and 7). Past study (Britch et al. 2018) has shown that low biting pressure (i.e., low collection numbers) in the earlier sample periods when the residual treatment is strongest makes efficacy analysis inconclusive.

For Trial 1, Aedes atlanticus Dyar and Knab, Anopheles crucians Wiedemann, Coquillettidia perturbans (Walker), Culex erraticus (Dyar and Knab), Culex nigripalpus Theobald, and Culex salinarius Coquillett fit this benchmark and were included in analyses. Collections for Culiseta melanura (Coquillett), though overall much lower than 1,000 individuals, were consistent across the period of Trial 1 so were included also.

For Trial 2, Ae. atlanticus, An. crucians, Cq. perturbans, and Cx. erraticus exceeded 1,000 individuals as in Trial 1, but Cs. melanura and Psorophora columbiae (Dyar and Knab) were also high. However, only 3 of these 6 species, Ae. atlanticus, An. crucians, and Cx. erraticus, 


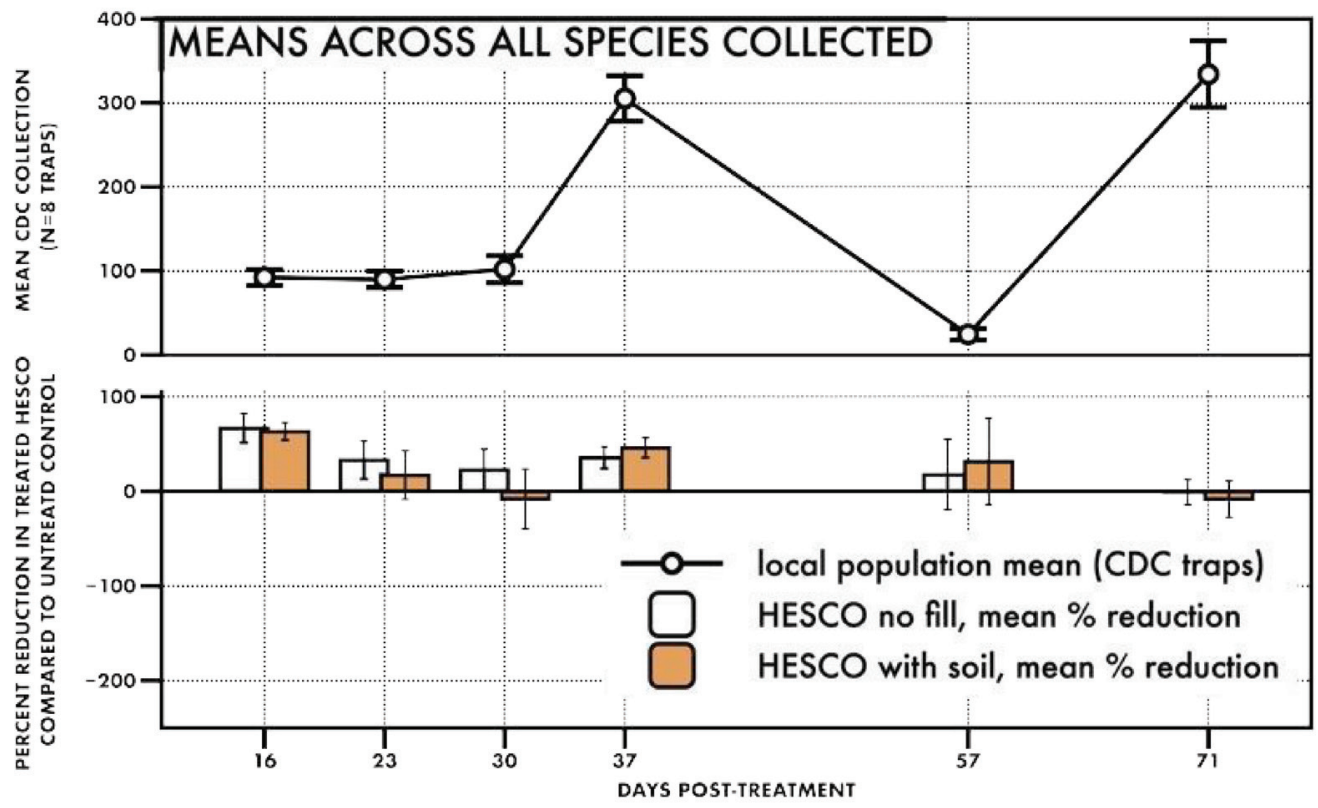

Figure 4. Trial 1 CDC light trap collection data for all species collected across the sample period; data for focal species across the sample period re shown in Supplementary Materials Figure S3, available at https://www.ars.usda. gov/cmave/mfru/HESCO. The upper section of each graph shows the local biting pressure indicated by collection means (with bars for standard errors of the mean, SEM) across the 8 outside CDC traps. The lower section shows the percent reduction in collections in treated HESCO perimeters compared to untreated ones, separated by whether soil was present. Bars below the zero line (negative values) signify that more mosquitoes were collected in treated perimeters - i.e., less control than untreated perimeters.

had substantial collections in the first 100 days post-treatment and analysis was restricted to these species for Trial 2. Also, though low overall, Culex restuans Theobald had high collection numbers in the first 100 days posttreatment and was included in the Trial 2 analysis.

In Trial 1, considering efficacy of the HESCO perimeters against all collected species combined, no soil and soil filled treated perimeters overwhelmingly showed reduction in trap counts - represented by bars above the x-axis - compared with untreated perimeters up through day 57 post-treatment (Figure 4). Collections from days 16, 37, and 57 post treatment indicate that soil filled treated HESCO perimeters showed a greater (days 37 and 57) or approximately equivalent (day 16) reduction in trap counts compared with no soil treated perimeters. The day 23 collections showed inferior performance of soil filled treated perimeters compared with no soil treated perimeters yet were still more effective than untreated soil filled perimeters. Finally, collections from days 30 and 71 post treatment show that populations were higher in the soil filled treated perimeters - represented by bars below the x-axis - compared with untreated soil filled perimeters.

If we separate percent reduction efficacy by species (Figure S3B-H), however, a spectrum of results emerges from Trial 1. For example, soil filled treated perimeters mostly outperformed no soil treated perimeters up to and including day 37 against Ae. atlanticus (Figure S3B), An. crucians (Figure S3C), and $C x$. salinarius (Figure S3G). In contrast, efficacy was more varied for $C q$. perturbans (Figure S3D), Cx. erraticus (Figure S3E), Cx. nigripalpus (Figure S3F), and Cs. melanura (Figure S3H) over the same time period. Also, the day 30 relative abundance of mosquitoes in soil filled treated perimeters when considering all collected species (Figure 4) 
is actually driven by only three species, $A n$. crucians, Cx. erraticus, and Cs. melanura which were to a greater or lesser extent asymmetrically more abundant in the soil filled treated perimeters. Conversely, on day $30 \mathrm{Cx}$. nigripalpus were less abundant in the soil filled treated perimeters and asymmetrically abundant in the no soil treated perimeters.

In Trial 2, the consistent and relatively superior percent reduction efficacy of the soil filled treated HESCO perimeters compared with no soil treated perimeters is apparent when considering all collected species through day 164 post treatment (Figure 5). One exception is day 71 collections where traps in soil and no soil treated barriers collected more mosquitoes - i.e., bars below the $\mathrm{x}$-axis - than either class of untreated barrier (Figure 5). Due to seasonally low populations early in the treatment period of Trial 2, only a few species (Figure S4B-E) can be examined individually to determine their contribution to the pattern in Figure 5. Unlike Trial 1, Ae. atlanticus collections (Figure $\mathrm{S} 4 \mathrm{~B}$ ) in Trial 2 were not uniformly lowest in the soil filled treated HESCO perimeters. However, except for the day 127 collections, soil filled treated perimeters in Trial 2 performed best against $A n$. crucians up to and including day 164 (Figure S4C). Although showing strong efficacy on day 127 against $C x$. erraticus (Figure S4D) and Cx. restuans (Figure S4E) the remaining periodic samples up to day 164 post treatment do not suggest that soil filled treated HESCO perimeters provided a more efficacious relative reduction compared with no soil treated HESCO.

Spring transitioned into summer between the days 189 and 218 sample periods in Trial 2, which corresponds to the large jump in collection numbers shown in Figure 5. Although combined collections on day 218 suggest that no soil and soil filled treated perimeters were less efficacious - i.e., bars below the x-axis - than untreated perimeters (Figure 5), subsequent collections on days 253, 281, and 344 indicate high or equivalent relative efficacy of soil filled treated HESCO perimeters. However, these periods are also punctuated by asymmetrically low efficacy of the soil filled treated HESCO on days 309 and 372 (Figure 5), largely driven by numbers from the An. crucians collections (Figure S4C).

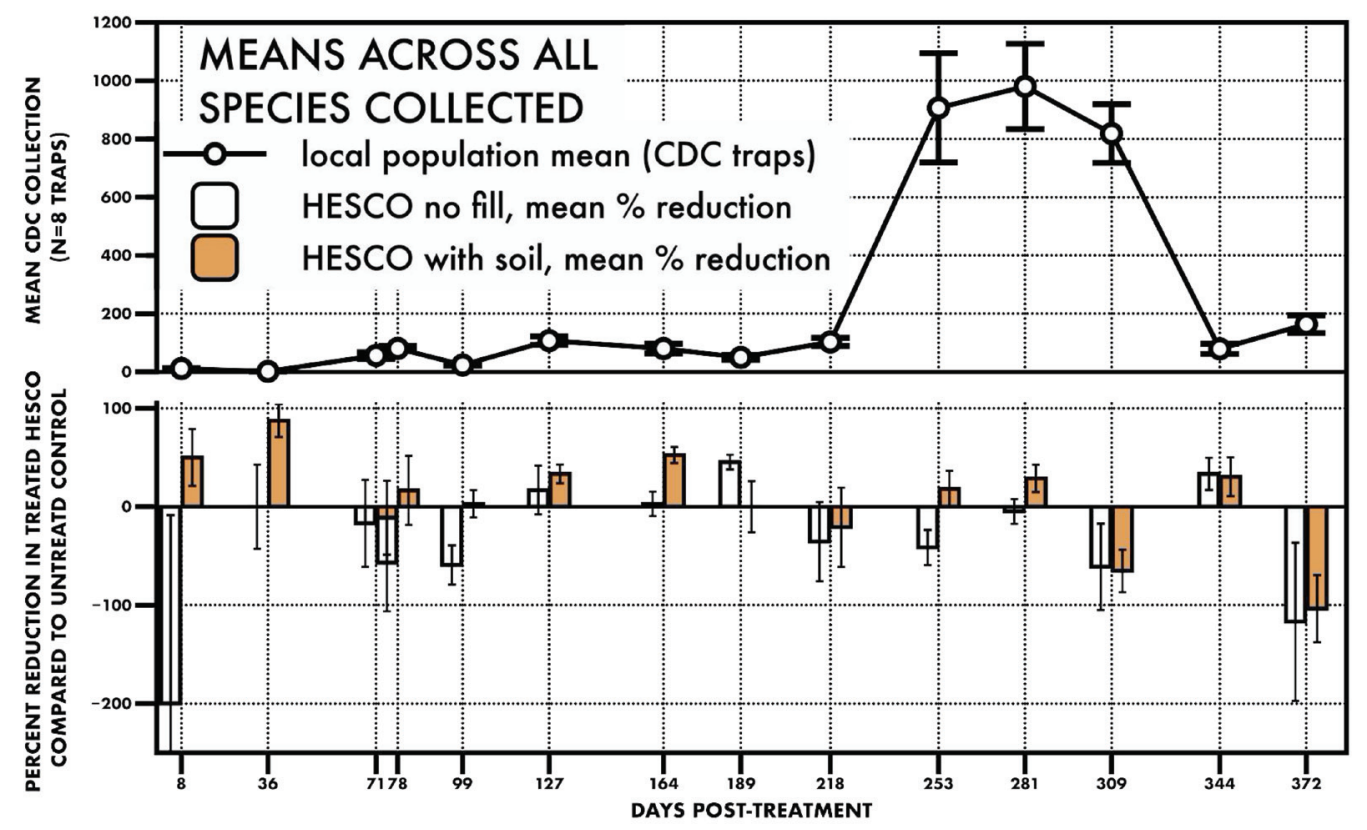

Figure 5. Trial 2 CDC light trap collection data for all species collected across the sample period; data for focal species across the sample period are shown in Supplementary Materials Figure S4, available at https://www.ars. usda.gov/cmave/mfru/HESCO. See Figure 4 legend for details. 

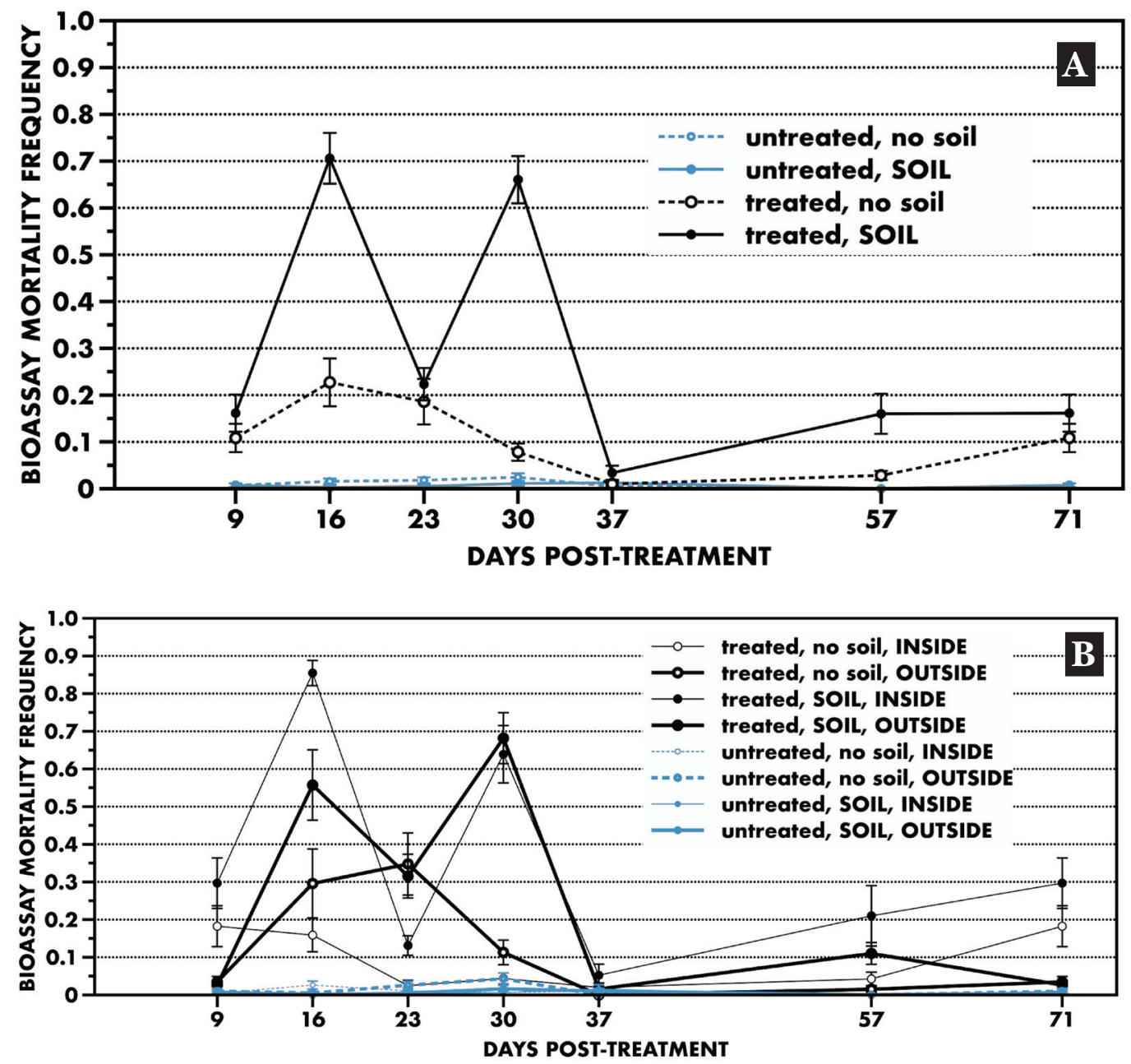

Figure 6. Mean percent Culex quinquefasciatus mortality following $24 \mathrm{~h}$ exposure in laboratory bioassays to insecticide-treated (black lines) and untreated (blue lines) HESCO geotextile samples from Trial 1, separated by no soil (dashed lines) and soil present (solid lines). Graph (A) presents combined mortality data across geotextile samples from both inside and outside the perimeters; graph (B) separates data from samples collected inside (not bold) and outside (bold lines) the HESCO perimeters.

\section{HESCO fabric bioassays}

Bioassay results are shown in Figs. 6 and 7 for Trials 1 and 2, respectively. In each figure, the first graph shows data from inside and outside geotextile samples combined and the second graph separates the inside and outside efficacy data. Curves for treated samples are black and the control sample curves are blue and generally clustered near zero. Bioassay efficacy data for both trials show a general trend of decline in efficacy over time, yet also show variation, sometimes ex- treme, between sample periods that indicate an apparent loss then restoration of efficacy. This phenomenon has been observed previously in pesticide treated material studies (Britch et al. 2010, 2011, 2018) and is likely a result of uneven treatment and/or uneven weathering that becomes evident as samples are cut from sequentially adjacent sections of treated surface. The phenomenon may be exaggerated when the initial treatment itself is weak, as seen in Trial 1 where the highest recorded efficacy was only $\sim 85 \%$ mortality (Figure 6B) and even then only for one sam- 

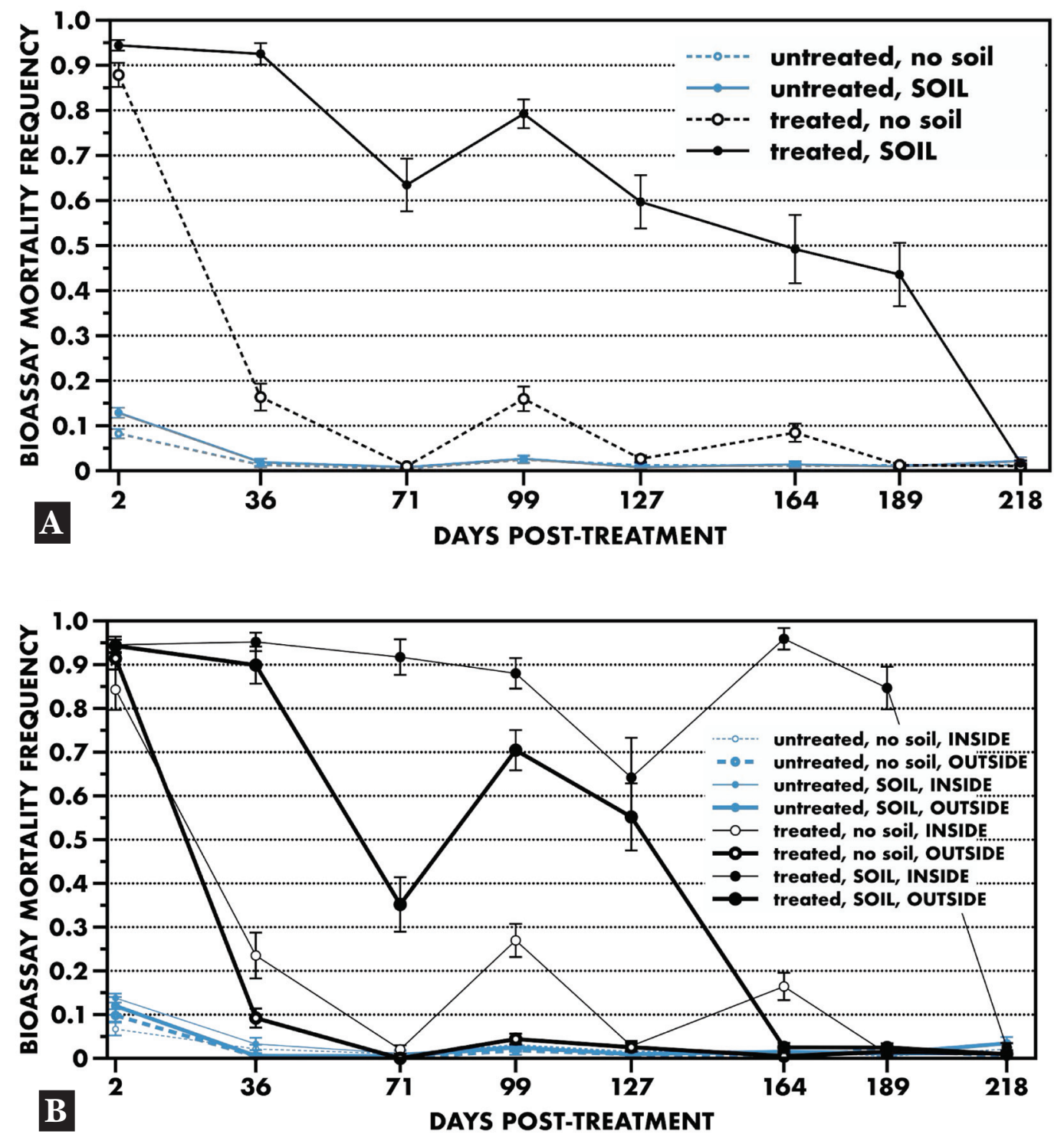

Figure 7. Mean percent Culex quinquefasciatus mortality following $24 \mathrm{~h}$ exposure in laboratory bioassays to HESCO geotextile samples from Trial 2. See Fig. 6 legend for details. Graph (A) presents combined mortality data across geotextile samples from both inside and outside the perimeters; graph (B) separates data from samples collected inside (not bold) and outside (bold lines) the HESCO perimeters.

ple period (day 16). The Trial 1 treatment was carefully applied at maximum label rate but the pesticide batch was not fresh and it is possible that light rainfall that same day had diluted some of the treatment on the HESCO geotextile before it had fully dried. The Trial 2 treatment was applied with a fresh batch of pesticide and no meteorological challenges to the proper drying and fixing of the treatment to the geotextile fabric, resulting in much less inter-sample variation in efficacy and overall much longer duration of the treatment (Figure 7).

\section{DISCUSSION}

In this study we filled a major gap in our understanding of the capabilities of residual treatments targeting disease vector insects applied to a prominent US military material 
used pervasively worldwide. In prior work we established that residual pesticides such as $\lambda$-cyhalothrin on HESCO geotextile could substantially reduce mosquito and sand fly entry into protected perimeters, but these investigations were conducted in a non-operational configuration - i.e., the HESCO blast protection walls were not filled with soil. In the present study we mirrored earlier investigations but with the improved condition that treated geotextile was exposed to soil fill. We sought to determine whether soil filled treated HESCO perimeters would still have lower CDC trap collection numbers and higher bioassay mortality than untreated perimeters, and whether longevity of the treatment would be affected by the presence of soil. We found that for the majority of collected species across most post-treatment sample periods, when bioassays indicated the treatment was still active, treated HES$\mathrm{CO}$ material exposed to soil fill was as good as or better than no soil treated HESCO at reducing entry of mosquitoes into the protected area.

Two major patterns emerge from the bioassay portion of this experiment: (i) the superior efficacy (amplitude and duration) of treated geotextile exposed to soil fill and (ii) the superior efficacy of treated material on the inside of the perimeter. These major patterns are less obvious in Trial 1 (Figure 6) possibly because of the exaggerated noise associated with the poor initial treatment, but the patterns are highly visible across the entire bioassay data set from Trial 2 (Figure 7). In Trial 1, bioassays on treated material not exposed to soil were consistently less efficacious (maximum just under $20 \%$ mortality at day 16 , Figure $6 \mathrm{~A}$ ) than treated material exposed to soil (maximum $70 \%$ at day 16). In Trial 2 within just over 1 month post treatment, treated HESCO geotextile not exposed to soil dropped from just under $90 \%$ mortality on day 2 to just over $15 \%$ mortality on day 34; whereas, treated material in the presence of soil remained above $50 \%$ mortality up to day 164 (Figure 7A)

In a previous study (Britch et al. 2018) we set an arbitrary minimum efficacy benchmark of $80 \%$ mortality in bioassays for re- sidual pesticide treatment of HESCO perimeters. Bioassays on samples from Trial 2 revealed that inner surfaces of soil filled treated HESCO perimeters continued to provide at least $85 \%$ mortality up to day 189 post treatment (Figure 7B). Toxicity of outside treated surfaces, however, substantially lost efficacious control within 2 months post treatment (Figure 7B). This pattern is also visible in the later (days 37-71) samples in Trial 1 where interior locations of both no soil and soil filled treated geotextile exceeded efficacy of the outside locations (Figure 6B). However, this pattern in Trial 1 is obscured early in the trial period by the high sample-to-sample variability in efficacy possibly due to the poor initial treatment (Figure $6 \mathrm{~B})$.

The periodic efficacy as shown by field collections in the soil filled treated perimeters late in the Trial 2 sample period long after bioassays indicate zero efficacy introduces the possibility that the field collections are not reliable indicators of efficacy, being perhaps more driven by spatial or microclimate effects. However, the combination of a high biting pressure and a waning or absent treatment will naturally lead to inconclusive results. On the other hand, the trend in field collections from Trial 2 showing more consistent superior or equivalent efficacy of soil filled treated perimeters early in the sample period up to day $160-$ despite lower field populations than Trial 1 early in the sample period - followed by a trend of less consistent efficacy later in the sample period (Figure 5), point to a reasonable match with the bioassay results that show a fall to zero efficacy between days 189 and 218 (Figure 7). Even with the poor initial treatment in Trial 1, we see more consistent superior or equivalent efficacy of soil filled treated perimeters up to day 57 in field collections (Figure 4) which nearly coincides with the loss of efficacy in bioassays between days 37 and 71 (Figure 6).

One key finding of this investigation is the heterogeneity of the residual treatment efficacy across mosquito species in the field environment. Implementation of residual treatment of HESCO geotextile should thus 
be carefully tempered by surveillance of local populations so that the relative likely contribution of the residual treatment in the local integrated vector management (IVM) program is understood. Adjustments should be made in other parts of the IVM program to support increased vigilance and control of species less prone to control from the perimeter treatment such as $C x$. erraticus or Cx. restuans as observed in Trial 2. In particular, prominent worldwide highthreat species such as Aedes aegypti and Aedes albopictus should be monitored closely for susceptibility to control with a residual barrier such as the one investigated herein.

Processes underlying the increased performance of the residual treatment when soil is present could include the buffering effect of soil moisture on temperature. The high specific heat capacity of water means that moistened material should take longer to heat up and longer to cool down than dry material. In addition, with soil present the material may have some level of moisture present for longer intervals which could make inundation with rainfall less of a shock to the chemistry of the residual formulation. Unfilled HESCO cells allow weathering to take place on both sides of the cloth, and there is increased mechanical action in unfilled HESCO because air currents can shake, fold, and abrade the fabric otherwise held still by the pressure of the soil fill. Although both treated and untreated soil-filled HESCO perimeters will have a warm, moist, and still-air microclimate in the interior protected space potentially attractive to resting mosquitoes, the treated soil filled HESCO also has a control measure: more mosquitoes may enter a soil filled perimeter, but may also be more likely to rest on the favorable, but toxic, surface. Additionally, we observed narrow $(3-9 \mathrm{~cm})$ vertical spaces between HESCO MIL cells in perimeters with no soil fill that allowed light and possibly $\mathrm{CO}_{2}$ from the CDC traps to project through the perimeters, possibly enhancing collections compared to soil filled HESCO perimeters that had no such gaps. The physical presence of the HESCO perimeters themselves seemed to act as a barrier to mosquito trap entry when compared to perimeter traps. Other processes underlying the increased efficacy of treated HESCO when soil is present could be the chemistry of the soil itself which may enhance the adhesive properties of the residual formulation, thus compelling future studies to consider efficacy across a variety of soil type exposures.

These findings provide deployed US military personnel responsible for mosquito control specific and attainable methodology to enhance management of mosquito vectors of malaria, dengue, Zika, yellow fever, and chikungunya in endemic settings. In particular, the technique of residual treatment of soil filled HESCO will also provide immediate mitigation for units that have been unable to adequately reduce malaria vectors because of nearby but physically inaccessible habitat where continuous mosquito production may occur. Likewise in nonmilitary scenarios, these findings provide emergency management personnel an additional tool for control of mosquito vectors and other biting flies after extreme weather events. HESCO barriers can be placed and treated prior to anticipated flood events to help protect residents from large numbers of mosquitoes that may emerge after hurricanes and heavy rains. Reduction of natural populations of disease vector mosquitoes following HESCO treatments is certainly not expected to be absolute and will likely vary by species but should be considered one layer in a multi-faceted pest and vector management system. This study was conducted in a warm temperate region using one soil type with one residual pesticide treatment formulation and application technology targeting mosquitoes, but should be repeated in other key militarily relevant environments including hot arid, hot tropical, Mediterranean, and cool temperate regions with additional soil types with more combinations of formulations and spray equipment, and in the presence of other important disease vectors such as sand flies. Post natural disaster flooding presents risks to public health worldwide and should also be included in design of future studies on treated HESCO geotextile. 


\section{ACKNOWLEDGEMENTS}

We thank Camp Blanding Joint Training Center (CBJTC) Environmental and DPW for permission to establish and access field sites and for lending soil; the $388^{\text {th }}$ Engineering Company (US Army Reserve) for providing and operating earth moving equipment to fill HESCO MIL cell perimeters; and C. McDermott and E. Moore for expert assistance in the field and lab. For expert production of colony insect specimens we thank H. Brown, T. Carney, K. Kern, B. Smith, C. Swain, D. Kline, J. Urban, H. Furlong, J. Hogsette, R. TenBroeck, W. Delaney, D. Johnson, C. Taylor, C. Geden, and R. White at the USDA-ARS-CMAVE insectaries. This research was supported by the US Department of Agriculture (USDA)-Agricultural Research Service and with a US Department of Defense (DoD) Defense Health Program DHP 6.715_I_15_J9_1124 grant to J. Cilek. Mention of trade names or commercial products in this publication is solely for the purpose of providing specific information and does not imply recommendation or endorsement by USDA, US Navy, DoD, or the Florida Army National Guard. Data in this study have been added to the Mobile Pesticide App operational entomology decision support system database (https://ars.usda. gov/saa/cmave/PesticideApp; Britch et al. 2014). The USDA is an equal opportunity provider and employer.

\section{REFERENCES CITED}

Aldridge RL, Wynn WW, Britch SC, Allan SA, Walker TW, Geden CJ, Hogsette JA, Linthicum KJ. 2013. High-throughput mosquito and fly bioassay system for natural and artificial substrates treated with residual insecticides. J Am Mosq Control Assoc 29:84-87.

Aldridge RL, Wynn WW, Britch SC, Linthicum KJ. 2012. Aspirator gun for high-throughput mosquito bioassays. J Am Mosq Control Assoc 28:65-68.

Britch SC, Linthicum KJ, Wynn WW, Walker TW, Farooq M, Smith VL, Robinson CA, Lothrop BB, Snelling M, Gutierrez A, Lothrop HD. 2009. Evaluation of barrier treatments on native vegetation in a southern California desert habitat. J Am Mosq Control Assoc 25:184-193.

Britch SC, Linthicum KJ, Wynn WW, Walker TW, Farooq M, Smith VL, Robinson CA, Lothrop BB, Snelling M, Gutierrez A, Lothrop HD. 2010. Residual mosquito barrier treatments on U.S. military cam- ouflage netting in a southern California desert environment. Mil Medicine 175:599-606.

Britch SC, Linthicum KJ, Wynn WW, Aldridge RL, Walker TW, Farooq M, Dunford JC, Smith VL, Robinson CA, Lothrop BB, Snelling M, Gutierrez A, Wittie J, White G. 2011. Longevity and efficacy of bifenthrin treatment on desert-pattern US military camouflage netting against mosquitoes in a hot-arid environment. J Am Mosq Control Assoc 27:272-279.

Britch SC, Linthicum KJ, Aldridge RL, Walker TW, Rush MJE, Aubuchon MD, Kerce JD, US Navy Entomology Center of Excellence Team. 2018. Residual pesticide on $\mathrm{HESCO}{ }^{\circledR}$ blast protection wall in temperate Florida habitat effective against mosquitoes, stable flies, and sand flies. J Am Mosq Control Assoc 34:224-232.

Darsie RF, Morris CD. 2003 (revised). Keys to the adult females and fourth-instar larvae of the mosquitoes of Florida (Diptera: Culicidae). Tech Bull Florida Mosq Control Assoc 1:1-159.

Dearstyne DA, Leach DE, Sullivan KJ. 1991. Soil Survey of Branford County, Florida. United States Department of Agriculture, Soil Conservation Service.

Duncan DB. 1951. A significance test for difference between ranked treatments in an analysis of variance. Virginia J Sci 2:171-189.

Duncan DB. 1955. Multiple range and multiple F tests. Biometrics 11:1-42.

Eisen L, Beaty BJ, Morrison AC, Scott TW. 2009. Proactive vector control strategies and improved monitoring and evaluation practices for dengue prevention. J Med Entomol 46:1245-1255.

Frances SP. 2007. Evaluation of bifenthrin and permethrin as barrier treatments for military tents against mosquitoes in Queensland, Australia. JAm Mosq Control Assoc 23:208-212.

Garcia MN, Cropper TL, Gunter SM, Kramm MM, Pawlak MT, Roachell W, Ronca SE, Stidham RA, Webber BJ, Yun HC. 2017. Vector-borne diseases of public health importance for personnel on military installations in the United States. US Army Med Dep J PN 8-17-1:90-101.

Gibson T. 2006. HESCO Bastion - A simple approach to flood protection and much more. Progressive Engineer. http://www.progressiveengineer.com/company_profiles/hesco.htm [accessed 22 May 2019].

HESCO Bastion Ltd. (GB). 2019. MIL TM Units. https:/ / www.hesco.com/products/mil-units/mil/ [accessed 22 May 2019].

Kitchen LW, Lawrence KL, Coleman RE. 2009. The role of the United States military in the development of vector control products, including insect repellents, insecticides, and bed nets. J Vector Ecol 34:50-61.

Kruskal WH, Wallis WA. 1952. Use of ranks in one-criterion analysis of variance. J Amer Statist Assoc 47:583621.

Müller WW, Saathoff F. 2015. Geosynthetics in geoenvironmental engineering. Sci Technol Adv Mater 16:034605.

Scheffe H. 1953. A method of judging all contrasts in the analysis of variance. Biometrika 40:87-104.

Scheffe H. 1959. The Analysis of Variance. NY: John Wiley. Scott TW, Morrison AC. 2004. Aedes aegypti density and the risk of dengue virus transmission. In: Takken W., Scott T.W, eds. Ecological aspects for application of genetically modified mosquitoes. Dordrecht, the Netherlands: Kluwer Academic Publishers. p 187-206. 
Stoops CA, Heintshcel B, El-Hossary S, Kaldas RM, Obenauer PJ, Farooq M, Villinski JT. 2013. Sand fly surveillance and control on Camp Ramadi, Iraq, as part of a leishmaniasis control program. J Vector Ecol 38:411-414.

Szabó S, Tóth R, Kovács Z. 2011. Force protection solutions with HESCO Bastion Concertainer. Acad Appl Res Mil Sci 10:31-59.

Tukey JW. 1949. One degree of freedom for non-additivity. Biometrics 5:232-242.

Tukey JW. 1953. The problem of multiple comparisons. Department of Statistics, Princeton University (unpublished).
US Army Corps of Engineers. 2006. Flood Fighting Structures Demonstration and Evaluation Program. US Army Corps of Engineers, Engineer Research and Development Center, Factsheet January 2006. Available at: https://web.archive.org/web/20060622211036/ http://chl.erdc.usace.army.mil/Media/6/7/8/FFSDPFactSheet1-2006.pdf [accessed 22 May 2019].

World Health Organization. 2014. A global brief on vectorborne diseases. Geneva: WHO.

Xue RD. 2008. Toxicity of permethrin-, malathion-, and fipronil-treated plant foliage to Aedes albopictus and Aedes aegypti. J Am Mosq Control Assoc 24:169-171. 